\title{
Effects of Fan-Aspirated Radiation Shield for Temperature Measurement in Greenhouse Environment
}

\author{
Seung Hwan Yang1, Chun Gu Lee ${ }^{2}$, Joon Yong Kim², Won Kyu Lee ${ }^{3}$, A. Ashtinai-Araghi ${ }^{2}$, Joong Yong Rhee ${ }^{2,4^{*}}$ \\ ${ }^{1}$ Center for Safety Measurement, Korea Research Institute of Standards and Science, Daejeon, Korea, ${ }^{2}$ Major of \\ Biosystems Engineering, Seoul National University, Seoul, Korea, ${ }^{3}$ Interdisciplinary Program for Bioengineering, Seoul \\ National University, Seoul, Korea, ${ }^{4}$ Research Institute for Agriculture and Life Sciences, Seoul National University, Seoul
}

Received: July $16^{\text {th }}, 2012$; Revised: August $23^{\text {th }}, 2012$; Accepted: August $30^{\text {th }}, 2012$

\section{Abstract}

Purpose: Provision of accurate temperature measurement is an essential element to ensure a precise control in greenhouse environment. This study was organized to compare the effects of six solar radiation shields with different shapes for temperature measurement and find the most appropriate shield for greenhouse environment. Methods: A fan-aspirated radiation shield was designed and manufactured. Using the fan-aspirated radiation shield and five other shapes i.e., the cup shape, horizontal pipe, vertical pipe, parallel boards and commercial shields, temperature measurement was conducted over the lawn surface as well as greenhouse indoor environment. The measurement height varied at $0.5,1.0$ and $1.5 \mathrm{~m}$ from the floor. Results: The measured temperatures by the fan-aspirated radiation shield were $1.30-1.49^{\circ} \mathrm{C}$ lower than the values recorded by other different-shaped shields at $1.5 \mathrm{~m}$ of measurement height. As the measurement height decreases, observed differences between measured temperatures of the fan-aspirated radiation shield and other shields demonstrate a declining trend. However, at low measurement heights, the radiation emitted from the bottom surface would be the source of error in temperature measurement. Conclusions: The fan-aspirated radiation shield is a required tool for exact measurement of air temperature in greenhouse temperature control.

Keywords: Asman psychrometer, CFD simulation, Greenhouse temperature, Solar radiation shield, Temperature measurement error

\section{Introduction}

Heating, cooling and ventilation are indispensable parts of the integrated working scheme for greenhouse operation. Since the greenhouse indoor temperature is the major determinant factor for these operations, development of methods and tools to measure exact temperature is intensely required. However, temperature values measured in the greenhouse usually include the errors arising from the solar radiation during the daytime. Accordingly, solar radiation shields are applied to reduce measurement errors. Many studies have been carried out on the performance of these

\footnotetext{
*Comesponding author: Joong Yong Rhee

Tel: +82-2-880-4605; Fax: +82-2-873-2049

E-mail: jyr@snu.ac.kr
}

solar radiation shields. Erell et al. (2005) compared several shapes of radiation shields and reported that the high airflow and small surface of sensor tip reduce the measuring error. A technique to block the solar radiation and generate airflow for the sensor tip is known as the Asman psychrometer. Passive solar radiation shields are widely used for meteorological observations. A passive type solar radiation shield reduces the measuring errors through the natural ventilation. However, temperatures measured in passive solar radiation shields may still include some errors. Richardson et al. (1999) have improved the error through the structural alert of multi-plate radiation shield. Nakamura and Mahrt (2005) have presented the radiative error-correction model using wind speed and radiation intensity to reduce the error. Nevertheless, due to closed 
configuration and isolated space of greenhouses, where the low air flow is the dominant state, it is hard to expect the benefits of error-reducing effects of the ventilation. Although some standard methods of air temperature measurement are provided for the meteorological observations (Ministry of Environment, 2008), standard methods for greenhouse environment have not been yet proposed. One of widely implemented methods is to use commercial solar radiation shields. However, these solar radiation shields are not optimized for greenhouse environment either. Therefore, it is necessary to find solar radiation shields suitable for greenhouse environment through comparing the effects of different solar radiation shields in the greenhouse environment and the meteorological observations condition.

The objective of this study was to compare the temperatures measured by several solar radiation shields in the greenhouse environment and the meteorological observations condition and to present an appropriate way to apply it for the greenhouse. A fan-aspirated radiation shield was designed and manufactured. The internal airflow of the developed radiation shield was simulated using computational fluid dynamic (CFD). In the comparison stage, five different shapes of the radiation shields including cup shape, horizontal pipe, vertical pipe, parallel boards and commercial passive solar radiation shields were prepared. Using these shields, temperature measurement was conducted over the lawn surface as well as greenhouse indoor environment on clear days. Consequently, necessity of aspirated radiation shield for measurement of the greenhouse indoor temperature was confirmed.

\section{Theory on the solar radiation shield}

The greenhouse environment is fully exposed to solar radiation while the natural movement and circulation of the inside air are slow and negligible in this environment. Single and interlinked effects of these two factors cause measurement errors of temperature. Based on the heat transfer theory (Holman, 2010), this error occurs due to the energy balance between the heat loss by convection and the heat input from radiation. Equation (1) shows the energy balance.

$$
h_{\mathrm{cv}}\left(T_{\infty}-T_{\mathrm{sr}}\right)=\varepsilon I_{\mathrm{solar}}
$$

where $h_{\mathrm{cv}}$ is the convection heat transfer coefficient on the sensor tip. $T_{\infty}$ and $T_{\text {sr }}$ are the ambient and sensor temperatures. $\varepsilon$ and $I_{\text {solar }}$ are emissivity of the sensor tip and solar radiation intensity. By rearrangement of equation (1) for temperature measurement error, $\left(T_{\infty}-T_{s r}\right)$, equation (2) is acquired.

$$
T_{\text {er }}=T_{\infty}-T_{\text {sr }}=\frac{\varepsilon I_{\text {solar }}}{h_{\mathrm{cv}}}
$$

Equation (2) shows that the temperature measurement error, $T_{\text {er, }}$ increases with the rise of solar emissive power while it steps down with the increment of convection heat transfer coefficient. According to this, the role of solar radiation shield is to block and prevent the solar radiation which will subsequently lead to the reduction of solar emissive power. In addition, if the solar radiation shield is equipped with a ventilating device, the convection heat transfer coefficient will be increased which implies a further decrease in temperature measurement error.

\section{Materials and Methods}

\section{Temperature measurement}

Temperature measurement was conducted using USB temperature loggers (GT171, Gilwoo, Korea). This temperature logger consists of a sensor, a data logger and a battery (Fig. 1). Sensor is a single chip module (SHT11, Sensiron, Switzerland). The accuracy of the device was $\pm 0.4^{\circ} \mathrm{C}$ for temperature. The temperature logger was embedded into the solar radiation shields. Recorded data were downloaded to the computer using the USB interface.

\section{Design and simulation of the fan-aspirated radiation shield}

The fan-aspirated radiation shield was designed to block solar radiation and aspirate the air by force. Once these two goals are achieved, multi-plate structure would not be necessary anymore. Thus, the structure of the fanaspirated radiation shield remains simple. Since the USB temperature logger has to be embedded inside the radi-

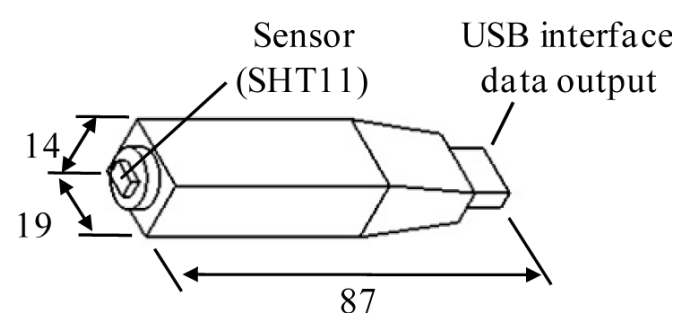

Figure 1. USB temperature logger (unit: $\mathrm{mm}$ ). 
ation shield, the radiation shield is designed to provide sufficient interior space. Figure 2 shows the structure and dimensions of the developed fan-aspirated radiation shield. A fan with $80 \mathrm{~mm}$ diameter was attached on the top of the guardian pipe to aspirate the inside air out while the fan is operated with a $12 \mathrm{~V}$ battery. The outside surface of the solar radiation shield was covered with aluminum foil to improve the reflection of solar radiation. It is necessary to assess the status of aspiration adequacy of the air surrounding the sensor. Because of small size of the sensor, the air velocity and direction around the sensor were estimated through CFD simulation.

The inside airflow was simulated using CFD software. GAMBIT 2.2.30 and FLUENT 6.2.16 were used for creation of geometries and meshes, and analysis of airflow, respectively. The viscous model used for the simulation was selected according to k- $\varepsilon$ standard which has been previously applied for various areas (Lee and Short, 2001; Bhattacharya et al., 2002; Yang et al., 2003; Zakrzewska et al., 2004). Conditions and meshes generated for the CFD simulation are listed in Table 1.

\section{Solar radiation shields to compare with the fan-aspirated radiation shield}

Various shapes of solar radiation shields have been

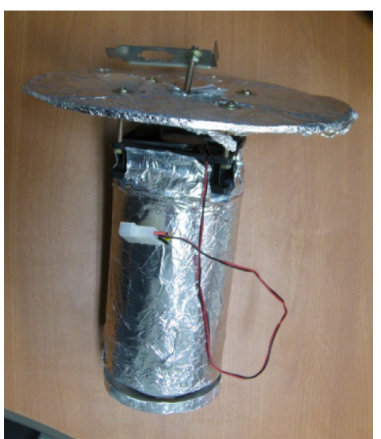

(a) View

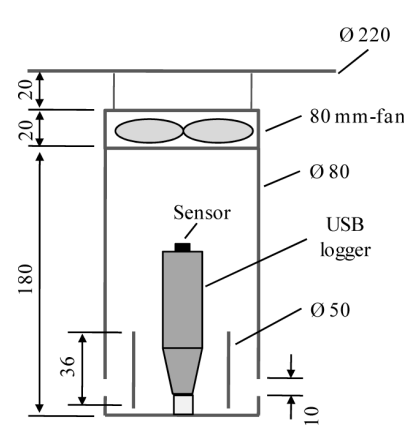

(b) Structure and dimension
Figure 2. Structure and dimensions of the fan-aspirated radiation shield (unit: $\mathrm{mm}$ ). proposed and evaluated (Peon et al., 1998; Ma et al., 2004; Erell et al., 2005). In this study, five shapes of solar radiation shields were chosen to be compared with the fan-aspirated radiation shield. The cup shape shield, an easy model to make and install in greenhouses, blocks most solar radiation from the upper side. The horizontal pipe shape blocks solar radiations originating from both upper and lower sides. In addition, the horizontal pipe shape has an effective structure in terms of natural ventilation around the sensor area. The horizontal pipe is similar to cup shape whereas the inside space is minimized in the latter design, and this enables to decrease the ventilation requirements. The parallel boards shape is designed to block solar radiation from both upper and lower sides and to maximize the effects of natural ventilation. Lastly, the commercial passive radiation shield is a device which is practically used in greenhouses. Their structures and dimensions are shown in Figure 3. All these shapes own simple structures which are easily manufactured or acquired from the market. The commercial passive solar radiation shield (7714, Davis Instruments, USA) is shown in Figure 4.

\section{Experimental set-up and environments}

A stand platform was set to place all six shapes of solar radiation shields at equal heights. This height was adjusted to be between $0.5 \mathrm{~m}$ and $1.5 \mathrm{~m}$. To measure solar radiation, a pyranometer (8-48, Eppley radiometer, USA) was installed at the center and top of the stand. Measured solar radiation intensity was recorded and transferred to the computer via the Labview device (USB-6259, National Instrument, USA). Figure 5 illustrates the experimental set-up for the effect comparison of 6 solar radiation shields.

The experiments were conducted at dual sites, i) above the lawn surface and ii) within a greenhouse. The total area of the lawn was approximately $20 \times 30 \mathrm{~m}$. This surface and environment, the lawn area of more than $70 \mathrm{~m}^{2}$, is accepted as the standard requirements for meteorological observations (Ministry of Environment, 2008). The greenhouse was an arch type plastic greenhouse with concrete paved

\section{Table 1. Analysis conditions for CFD simulation}

\begin{tabular}{|c|c|c|}
\hline Category & Item & Value \\
\hline \multirow{2}{*}{ Mesh generation } & Number of mesh & 112,749 (Hexahedron only) \\
\hline & EquiAngle Skew & Max. 0.43 \\
\hline \multirow{3}{*}{ Simulation conditions } & Viscous model & Standard $\mathrm{k}-\varepsilon$ \\
\hline & Outlet & $2.0 \mathrm{~m} / \mathrm{s}$ \\
\hline & Fluid & air \\
\hline
\end{tabular}




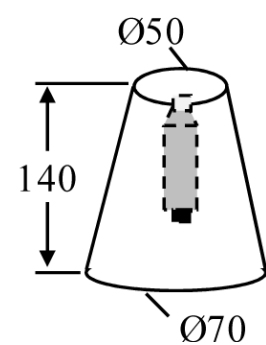

(a) cup shape

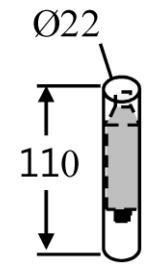

(c) vertical pipe

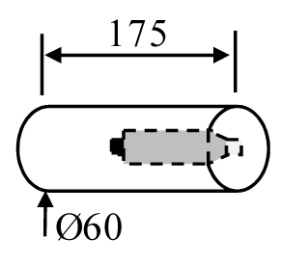

(b) horizontal pipe

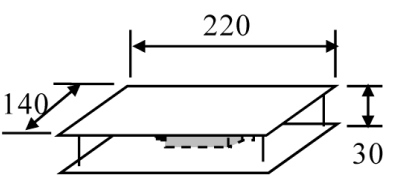

(d) parallel boards

Figure 3. Shapes of solar radiation shields selected for comparison experiment and installation position of USB temperature loggers (unit : mm).

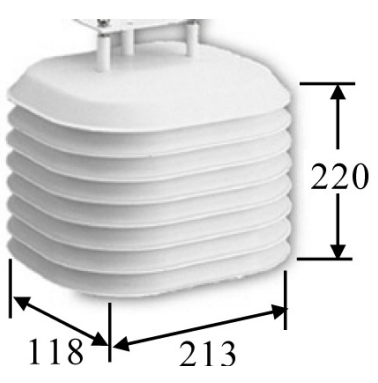

(a) structure and dimension

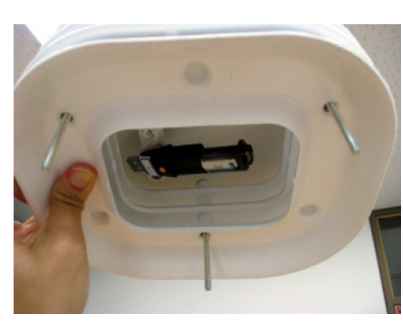

(b) USB logger installation

Figure 4. Structure and dimensions of the fan-aspirated radiation shield (unit: $\mathrm{mm}$ ).

floor, in which the top height was $5.5 \mathrm{~m}$. Many plant pots were placed on the floor at experiment time. The views of both experimental sites are shown in Figures 6 (a) and (b).

\section{Experimental procedure}

Air temperature was measured between 11:00 am and 3:00 pm at 10 second intervals during the clear days in the fall. Because the height of temperature measurement is determined by the plant canopy, the effects of solar radiation shields according to measurement height were analyzed. The height between the shields and floor varied to be at $0.5 \mathrm{~m}, 1.0 \mathrm{~m}$ and $1.5 \mathrm{~m}$ levels. Under the assumption that temperature measurement offered by fan-aspirated radiation shield is the most accurate, temperature values measured by fan-aspirated shield were set as the reference values. Subsequently, temperatures measured in other solar radiation shields were compared with the reference

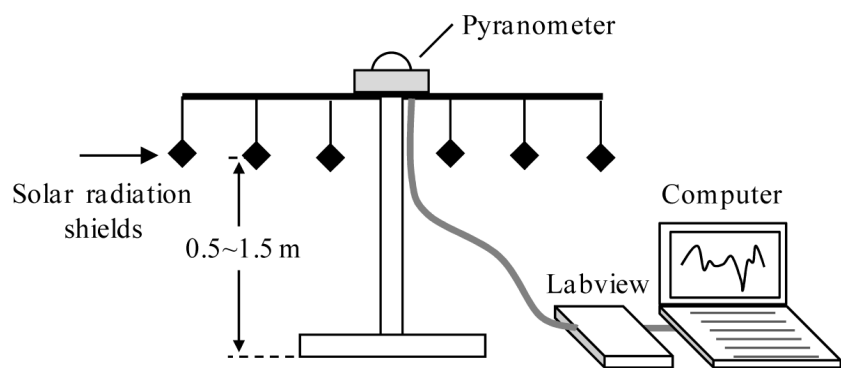

Figure 5. Experimental set-up for the effect comparison of 6 solar radiation shields.

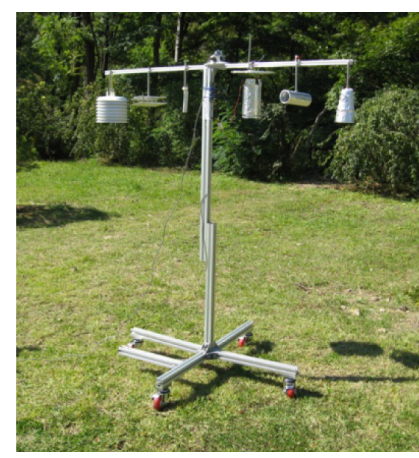

(a) above the lawn

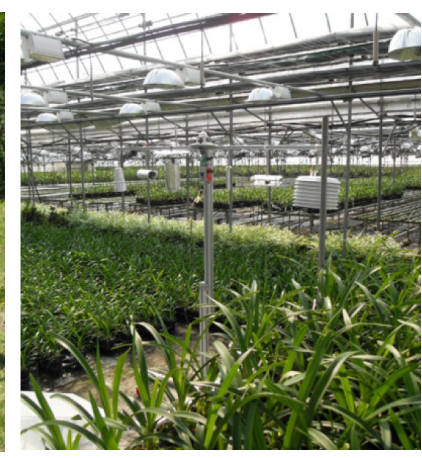

(b) within the greenhouse
Figure 6. Views of experimental set-up and environments.

temperature. Therefore, the effect of solar radiations was analyzed with temperature differences.

\section{Results and Discussion}

\section{Simulation result of designed fan-aspirated radiation shield}

The result of airflow simulation analysis is shown in Figure 7. Due to structural disturbance of the USB logger, air velocity at sensor tip was relatively slow (Fig. 7 (a)) and eddy was established around the sensor tip (Fig. 7 (b)). However, airflow around the sensor tip shows a velocity of $0.5-0.7 \mathrm{~m} / \mathrm{s}$ which implies the designed fan-aspirated radiation shield was proper and well-fitted for the experimental purpose.

\section{Temperature difference according to the solar radiation shields}

Temperatures were measured using six different solar radiation shields: vertical pipe, horizontal pipe, parallel boards, cup shape, commercial passive and fan-aspirated radiation shields. Figure 8 shows the measured temperatures using these shields at $1.5 \mathrm{~m}$ height. As expected, the 

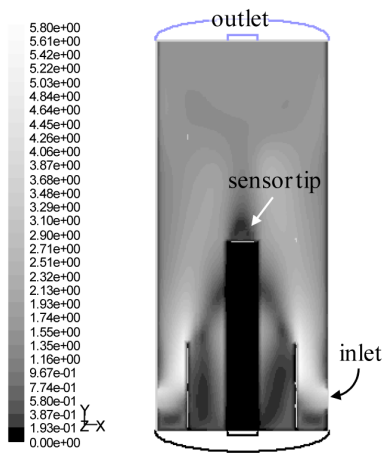

(a) velocity distribution

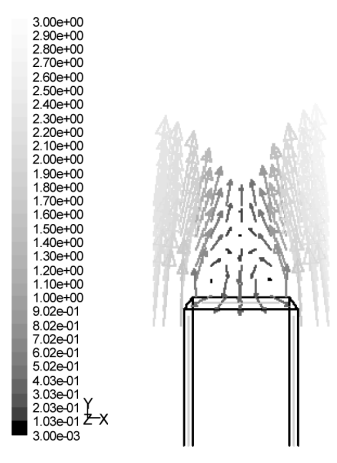

(b) air flow on the sensor tip
Figure 7. Air flow analysis in the fan-aspirated radiation shield through CFD simulation.

temperatures measured in the fan-aspirated radiation shield were the lowest. In the case of comparison over the lawn, measured temperatures in commercial passive and horizontal pipe solar radiation shields were not different from the ones in fan-aspirated shield within the sensor accuracy. Measured temperatures in vertical pipe, parallel boards and cup shape shields were $2.6-5.2^{\circ} \mathrm{C}$ and $1.3-4.8^{\circ} \mathrm{C}$ higher than the ones in fan-aspirated shield, at above the lawn and within the greenhouse sites, respectively. Assuming that the temperatures measured in fanaspirated radiation shield are the most accurate, these temperature differences can be regarded as the measurement errors caused by solar radiation.

Figure 9 shows the average values of observed temperature differences between fan-aspirated radiation and other different shaped shields. Remarkably, minimum difference was found in the commercial shield where the temperature difference increased from $0.69^{\circ} \mathrm{C}$ at above the lawn site to $1.30^{\circ} \mathrm{C}$ at greenhouse interior. This result shows that the method for the meteorological observation is not suitably applicable for greenhouse environment. The reason for increase in the difference may be attributed to the low amounts of airflow in the greenhouse. This would be interpreted as a relatively lower airflow makes smaller values for convective heat transfer coefficient on the sensor tip which results in high measurement errors, in turns.

High measurement errors in parallel boards shield ascertain that the solar radiation transmitting from sides of the shield is influential on easily reachable sensor tip. However, horizontal pipe shield shows a measurement error as low as the commercial passive shield. Thus, the horizontal pipe shield may be the economically feasible option for temperature measurement of the greenhouse.

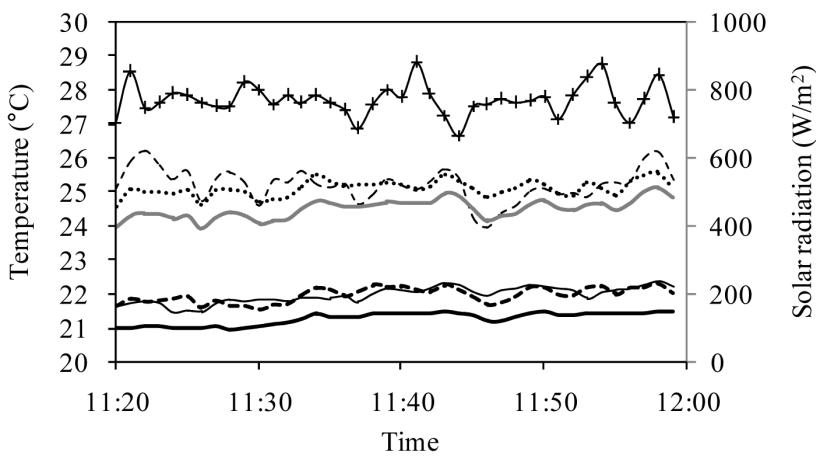

(a) above the lawn

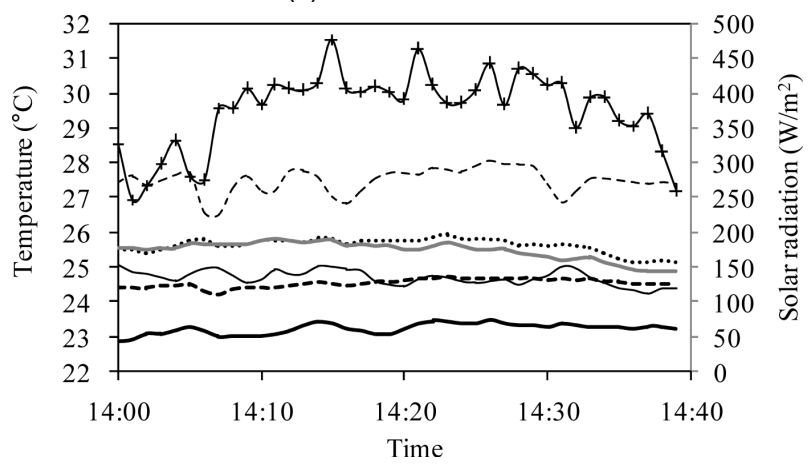

(b) within a greenhouse

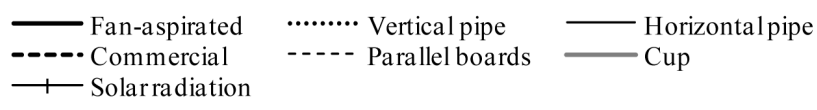

Figure 8. Temperatures measured with various solar radiation shields above the lawn and within a greenhouse.

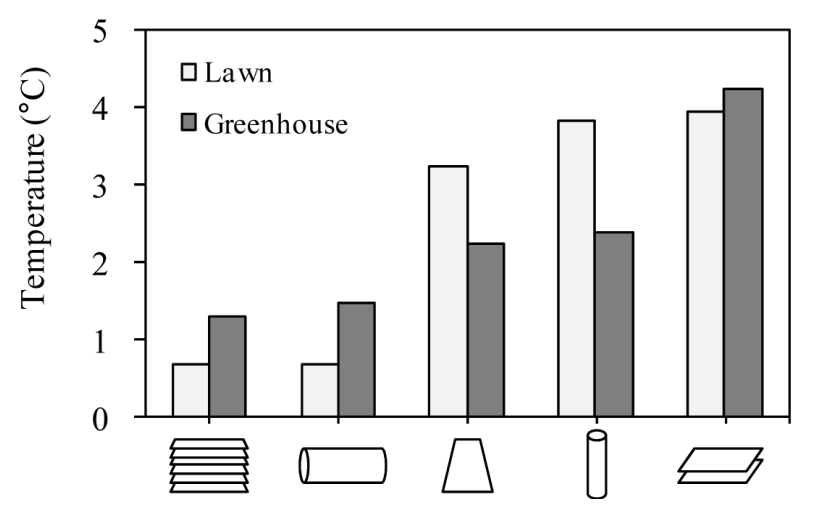

Figure 9. Temperature differences according to the shapes of the solar radiation shield compared with fan-aspirated shield (Symbols are referred to Fig. 3).

Interestingly, in spite of low airflow, cup and vertical shape shields showed lower measurement errors within the greenhouse than those observed above the lawn. This result implies that the reflected radiation from the floor has substantially influenced on the sensor. This relatively reduces the effect of natural ventilation factor which corrects the temperature measurement error. There are 
two effective and responsible environmental features for this result in the greenhouse. First one is that the amount of solar radiation in the greenhouse diminishes as a result of greenhouse covers. The second one refers to the larger number of plants on greenhouse floor which generally prevents the radiation reflection. It is notable to mention that the commercial, horizontal and parallel radiation shields, which block the radiation from the floor due to their structure, did not show the above described phenomenon.

\section{Temperature difference according to measurement height}

Average temperature differences between fan-aspirated radiation shield and others are shown in Figure 10. These temperature differences were generally decreased at lower measurement heights. In the case of the experiment over the lawn, the temperatures measured in horizontal pipe and the commercial passive shields were lower than the temperatures measured in fan-aspirated shield at $0.5 \mathrm{~m}$ of measurement height (Fig. 10 (a)). Such phenomenon might be caused by the radiation from the lawn which could be lower than ambient air temperature. Since the greenhouse was filled with plant pots, diverted radiation from the plants may have partly effects on the measurement at the points close to the floor. Apparently, the temperature differences between the fan-aspirated shield and others were decreased. However, considering the influence of sun, plants and floor radiations on temperature measurement, the fan-aspirated radiation shield is more suitable for the exact temperature measurement in compare to five other options. Due to large fluctuations of measuring temperatures at $0.5 \mathrm{~m}$ height above the lawn (Fig. 10 (a)), it is difficult to verify a significant relation between reduction in errors and lower measurement height. Temperature measured by the horizontal pipe shield showed the largest fluctuations at $1.0 \mathrm{~m}$ of height (Fig. 10 (b)). This result reveals that the horizontal pipe shield is susceptible to side radiations which cause measurement error.

Finally, commercial radiation shield can be a primary choice if solar radiation shield is to be used for greenhouse application. If the commercial shields are not provided, horizontal pipe, cup shape or vertical pipe shields can be next temporarily choices, considering that the measurement error may lie within $1.0-2.7^{\circ} \mathrm{C}$. However, because of inevitable existence of temperature measurement error which is enlarged for all shapes of the passive radiation

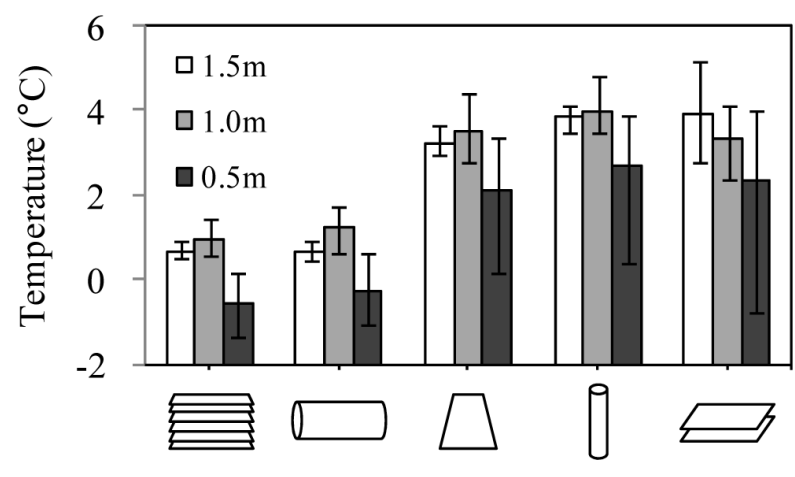

(a) above the lawn

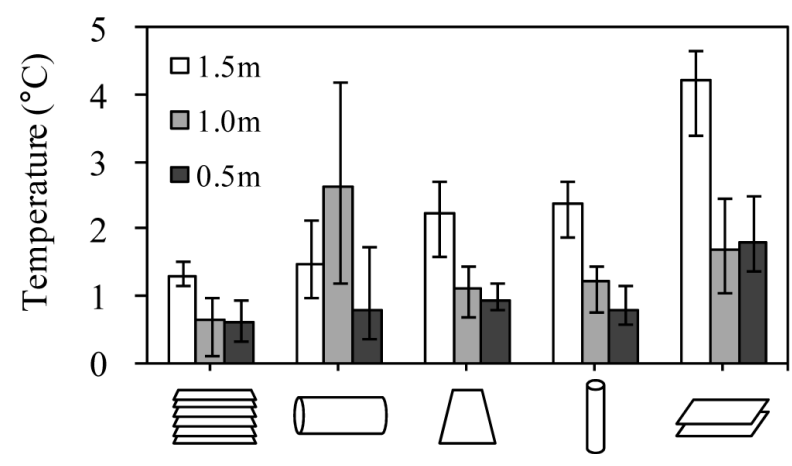

(b) within a greenhouse

Figure 10. Average temperature differences between fan-aspirated shield and other shields according to measurement height (Symbols are referred to Fig. 3).

shields in greenhouses, application of fan-aspirated radiation shields is recommended in the greenhouse environment.

\section{Conclusions}

This study was conducted to compare the effects of solar radiation shields on temperature measurement between greenhouse environment and meteorological observation conditions. A fan-aspirated radiation shield was designed and manufactured, and temperatures measured in this shield were compared with temperatures measured in five different shapes of the radiation shields, vertical pipe, horizontal pipe, parallel boards, cup shape and commercial passive solar radiation shields.

As a result, temperatures measured in fan-aspirated radiation shield were lower than temperatures measured in other types. Although the commercial passive and horizontal pipe radiation shields showed similar temperature measurement results with fan-aspirated radiation shield above the lawn, these temperature differences were 
increased by $1.30^{\circ} \mathrm{C}$ and $1.49^{\circ} \mathrm{C}$ within the greenhouse, respectively. In addition, at low measurement height, differences between recorded temperatures of fanaspirated shield and other types decreased. However, low temperature radiations from plants still affected the temperature measurement. The temperature difference compared with fan-aspirated radiation shield was commonly lower, ordered by commercial passive, horizontal pipe, cup shape, vertical pipe and parallel board radiation shields. This study objectively showed that the passive commercial radiation shield is not the suitable case to measure air temperature within greenhouses.

Consequently, the fan-aspirated radiation shield is required to measure the exact temperature in greenhouse environment. Furthermore, the shape of the fan-aspirated radiation shield can be simpler than the current commercial one involving a complicated multi-plate structure. Although the fan-aspirated radiation shield needs a power supply, this problem can be easily resolved by adding a power line when the sensor wire is connected to the controller in the temperature control greenhouse.

\section{Conflict of Interest}

No potential conflict of interest relevant to this article was reported.

\section{Acknowledgements}

This Study was supported by Technology Development Program for Agriculture and Forestry, Ministry for Food, Agriculture, Forestry and Fisheries, Republic of Korea.

\section{References}

Bhattacharya, S. and S. M. Kresta. 2002. CFD Simulations of Three-Dimensional Wall Jets in a Stirred Tank. The
Canadian Journal of Chemical Engineering 80(4): 1-15.

Erell, E., V. Leal and E. Maldonado. 2005. Measurement of Air Temperature in the Presence of a Large Radiant Flux: An Assessment of Passively Ventilated Thermometer Screens. Boundary-Layer Meteorology 114: 205-231.

Holman, J. P. 2010. Heat Transfer. New York, McGrawHill. pp.459-460.

Lee, I. B. and T. H. Short. 2001. Verification of Computational Fluid Dynamic Temperature Simulation in a Full-Scale Naturally Ventilated Greenhouse. Transactions of the ASAE 44(1): 119-127.

Ma, J., W. J. Bock and W. Urbanczyk. 2004. Error Analysis of Temperature-Compensated White-Light Interferometric Fiber-Optic Strain Sensor. Sensors and Actuators A: Physical 112(1): 25-31.

Ministry of Environment. 2008. Law on Meteorological Observation Standardization 2-1-1.

Nakamura, R. and L. Mahrt. 2005. Air Temperature Measurement Errors in Naturally Ventilated Radiation Shields. Journal of Atmospheric and Oceanic Technology 22(7): 1046-1058.

Peón, G., A. Camón, E. Martínez, C. Rillo, J. Sesé and R. Iturbe. 1998. Experimental Analysis of Thermalisation and Emissivity of Radiation Screens for Cryostat Design. Cryogenics 38(10): 953-958.

Richardson, S. J., F. V. Brock, S. R. Semmer and C. Jirak. 1999. Minimizing Errors Associated with Multiplate Radiation Shields. Journal of Atmospheric and Oceanic Technology 16(11): 1862-1872.

Yang, G. M., H. K. Koh and J. H. Hong. 2003. Development of Dome-Type Cold Storage Facility Using 3-D CFD Simulation. Journal of the Korean Society of Agricultural Machinery 28(1): 35-44.

Zakrzewska, B. and Z. Jaworski. 2004. CFD Modeling of Turbulent Jacket Heat Transfer in a Rushton Turbine Stirred Vessel. Chemical Engineering \& Technology 27(3): 237-242. 